\title{
THE RELATIVE IMPORTANCE OF PROCESSES AFFECTING RECRUITMENT OF TWO TEMPERATE REEF FISHES
}

\author{
MARK A. SteEle ${ }^{1}$ \\ Department of Biological Sciences, University of California, Santa Barbara, California 93106 USA
}

\begin{abstract}
Local population densities of most benthic marine organisms are determined by a variety of processes that act before, during, and after settlement of planktonic propagules to the benthos. Considerable disagreement exists over the relative contribution of each process to patterns of abundance. Using multifactorial experiments, I assessed the effects of resident conspecifics, potential interspecific competitors, predators, and reef location on patterns of recruitment of two temperate reef fishes.

Recruitment of bluebanded gobies (Lythrypnus dalli) and blackeye gobies (Coryphopterus nicholsii) consistently increased with distance from a nearby large reef. Recruitment of Lythrypnus was enhanced by the presence of older resident conspecifics. I found no strong evidence of any competitive effects between the two species. Predators had a variety of important effects on the density of recruits. Recruitment of Lythrypnus was halved by predators; this was the result of direct and indirect effects of predators: in addition to directly reducing recruit density, predators also reduced recruitment indirectly by reducing the density of older residents to which recruits responded. I developed two related methods for quantifying the contributions of the direct and indirect components of the predator effect. The effect of predation was spatially variable for both species: the net effect of this variability was the elimination of recruitment patterns related to reef location. Hence, the effects of spatially variable input of recruits was dependent upon the presence of predators, and thereby, predation altered the relative importance of the other factors that affected recruitment of the gobies. I argue that a much broader understanding of the "relative importance" of multiple causal processes will be gained by striving to understand how the contribution of each process is modified by other processes than by attempting to quantify the "importance" of each process.
\end{abstract}

Key words: competition; Coryphopterus nicholsii; gobies; interacting processes, relative importance of; Lythrypnus dalli; multifactorial experiments; predation; recruitment, facilitation of; reef fish; spatial variation.

\section{INTRODUCTION}

Population attributes of species in nature are often shaped by multiple causal processes (e.g., Quinn and Dunham 1983, Welden and Slauson 1986, Hixon 1991, Jones 1991, Sale 1991). This realization represents a shift from past perspectives, which often treated different causal processes as alternatives. If we accept that populations are affected by a variety of processes, then a central question is, what is the "relative importance" (sensu Welden and Slauson 1986) of each process? Although many processes may act on a population, it may be the case that one (or a few) primarily determines the attributes of that population.

For organisms that have complex life histories involving a dispersive stage and a more sedentary stage (e.g., most marine organisms, many terrestrial plants, and many terrestrial and aquatic insects), the local

Manuscript received 15 March 1995; revised 21 February 1996; accepted 13 March 1996; final version received 10 April 1996.

${ }^{1}$ Present address: Department of Biology, University of California, 405 Hilgard Avenue, Los Angeles, California 90095-1606 USA. abundance of the sedentary stage is set by a balance between input of dispersing individuals and loss of sedentary individuals. These sorts of organisms usually have "open" (sensu Caswell 1978) local populations, since input to each local population does not come primarily from individuals locally produced, but instead comes from individuals produced by other populations. The relative importance of pre- vs. post-dispersal processes, in determining abundance in such open populations, is not well known (Connell 1985, Underwood and Fairweather 1989, Sale 1990). I explored this issue using two temperate marine reef fishes.

Most marine reef fishes have complex life histories: relatively sedentary adults produce larvae that spend weeks or months in the plankton, during which time they potentially travel great distances from their source populations, and finally they settle onto reefs where they become relatively sedentary and mature into adults. Hence, the abundance of juveniles and adults on a reef is determined by processes that affect the abundance of larvae that reach the reef, processes that affect settlement to the reef, and processes that affect 
individuals established on the reef. Input of larvae into reef-associated populations of fishes can be extremely variable in space and time (Doherty and Williams 1988, Underwood and Fairweather 1989, Sale 1990, Doherty 1991), yet the consequences of this variable input remain uncertain (Hixon 1991, Jones 1991, Sale 1991). The role that variation in larval input plays in creating variation in abundance among local populations is dependent on the extent to which settlement and postsettlement processes modify the patterns created by larval supply (Warner and Hughes 1988). I explored the extent to which natural spatial variation in input was modified by settlement and postsettlement processes in the bluebanded goby (Lythrypnus dalli) and the blackeye goby (Coryphopterus nicholsii).

I focused on three reef-associated processes: predation, interspecific competition, and intraspecific interactions. I assessed the effects on population density of the three processes relative to one another, and relative to concurrent natural patterns of spatial variation in input of juveniles (measured as recruitment). While each of the processes that I investigated has been demonstrated to affect abundance or individual performance of fishes (e.g., predation: Doherty and Sale 1985, Shulman 1985a, Behrents 1987, Hixon and Beets 1993, Carr and Hixon 1995; interspecific competition: Hixon 1980, Larson 1980, Schmitt and Holbrook 1990; intraspecific interactions: Doherty 1982, 1983, Sweatman 1983, 1985, Jones 1987a, b, 1990, Forrester 1990, 1995; spatially variable recruitment: Victor 1983, 1986, Shulman 1985a, b), most studies have focused on only one process at a time, and hence, it has been difficult to compare the strength of the effects of each process. In this study, I conducted a set of multifactorial experiments to evaluate the relative importance of these processes.

\section{Natural history}

Lythrypnus dalli and Coryphopterus nicholsii are common residents of rocky reefs in southern California, USA and northern Baja California, Mexico (Miller and Lea 1976). Lythrypnus is a small $(<50 \mathrm{~mm}$ standard length [SL]) brilliantly colored fish that lives no more than $2 \mathrm{yr}$ (Behrents 1983). It occurs only in rocky areas and reaches maximal densities $>100 / \mathrm{m}^{2}$. Crevices are used by this species for both shelter and nest sites, and additional shelter sites are provided by the spines of the sea urchin Centrostephanus coronatus. Coryphopterus is a larger (up to $90 \mathrm{~mm} \mathrm{SL}$ ), longer-lived (reaching $5 \mathrm{yr}$ of age), drab-colored fish that reaches its highest densities $\left(\approx 20\right.$ individuals $\left./ \mathrm{m}^{2}\right)$ in areas where rocky reefs meet sand. Coryphopterus generally matches its color to the sand and uses rocky overhangs, crevices, and empty mollusk shells for shelter and as nest sites. Both gobies are primarily planktivorous, although $\mathrm{Co}$ ryphopterus includes more benthic prey in its diet (M. A. Steele, unpublished data). Individuals of both species spend most of their time resting on the substrate

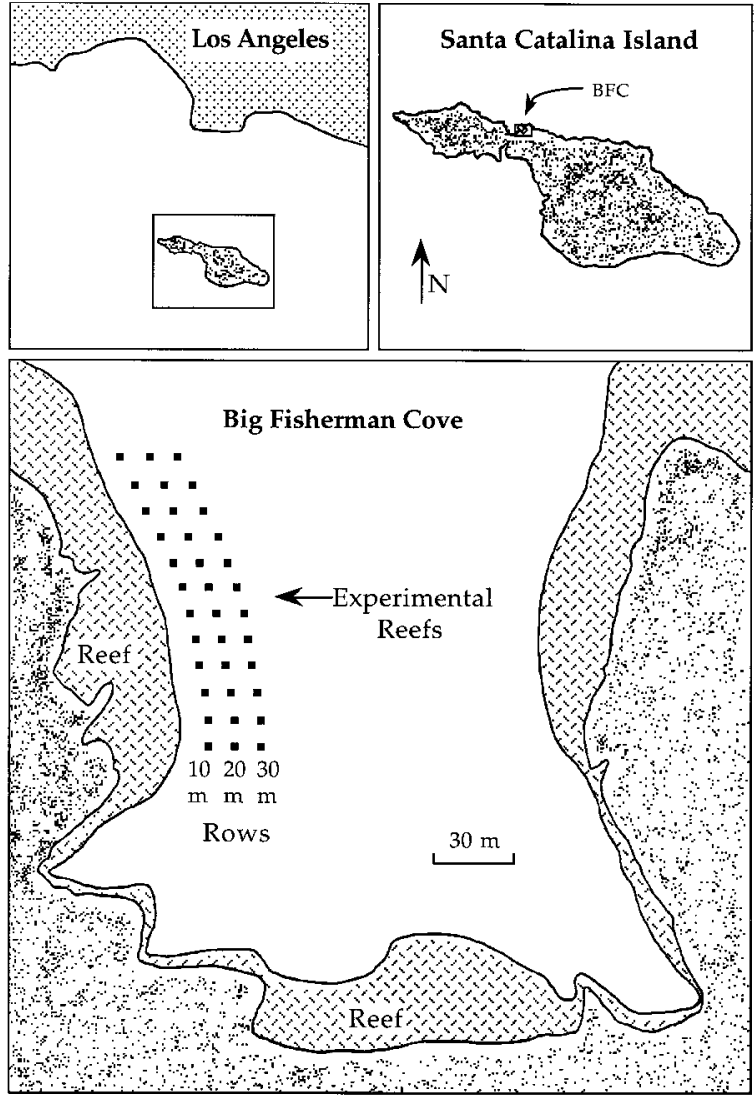

FIG. 1. Maps showing the position of Santa Catalina Island relative to the coast of southern California, the location of Big Fisherman Cove (BFC) on the island, and the spatial arrangement of experimental reefs within the cove.

(rocks or sand). This behavior is interrupted by brief foraging bouts in the water column and short spurts of agonistic behavior primarily directed at conspecifics (but occasionally focused on heterospecific gobies) (Steele 1995).

Males of both species defend nests of demersal eggs during spring through fall (Wiley 1973, 1976; M. A. Steele, personal observation); the larvae of both species then enter the plankton for 2-3 mo (M. A. Steele, unpublished data). Settlement of Lythrypnus starts in late May, peaks in July and August, and ends in January (Behrents 1987). At settlement, individuals are 9-11 mm SL (Behrents 1987). Larval Coryphopterus settle throughout the year, with a peak in early summer (JuneJuly); size at settlement ranges from 15 to $29 \mathrm{~mm} \mathrm{SL}$ (Wiley 1973; M. A. Steele, personal observation).

Upon completion of the planktonic stage, both gobies are susceptible to reef dwelling predators. At Santa Catalina Island $\left(33^{\circ} 27^{\prime} \mathrm{N}, 118^{\circ} 29^{\prime} \mathrm{W}\right.$; $35 \mathrm{~km}$ off the coast of southern California; Fig. 1), where my work was conducted, the kelp bass Paralabrax clathratus (Serranidae) is the main predator of the two gobies. Overall, kelp bass comprise $\approx 90 \%$ of all piscivorous predators at Santa Catalina Island (M. A. Steele, un- 
published data), and this numerical dominance is maintained in all microhabitats used by the gobies. Kelp bass actively and effectively hunt both gobies; neither species ever grows large enough to escape predation by bass. The only species other than kelp bass that I have observed actively hunting the two gobies is the very similar $P$. nebulifer (the barred sand bass). At a coastal site, Wiley (1973) found that $32 \%$ of the barred sand bass had consumed Coryphopterus (he did not mention whether Lythrypnus were included in the diet of sand bass, or whether this goby was even present at his site). Three labrids common at my site (the sheephead Semicossyphus pulcher, the rock wrasse Halichoeres semicinctus, and the señorita Oxyjulis californica) may occasionally prey upon the gobies, but they do not actively hunt them and they are not considered to be piscivorous.

\section{Methods}

\section{Study site}

At Santa Catalina Island, I conducted three experiments on the south side of Big Fisherman Cove (BFC) on standardized rock rubble reefs constructed over a sandy area that was bordered on one side by a rocky reef (Fig. 1). The species of predators found in this area are the same as those found in the habitats where the gobies reside on natural reefs. Observational studies were conducted on various rocky reefs located within $1 \mathrm{~km}$ of Big Fisherman Cove.

\section{Experiments}

I conducted three experiments to explore some of the factors that could potentially affect recruitment of Coryphopterus and Lythrypnus. The first two experiments (Experiment 1: 12 July-6 August 1992; Experiment 2: 15 August-8 September 1992) investigated the effects of resident Lythrypnus and Coryphopterus juveniles and adults on recruitment of both species, in the absence of predators. The third experiment (Experiment 3: 19 July-12 August 1993) simultaneously explored the effects of residents of both goby species and predators on recruitment.

All experiments were done on a grid of replicate $1-\mathrm{m}^{2}$ rock rubble reefs constructed on the sand bottom of Big Fisherman Cove (Fig. 1). To minimize differences in shelter and nest site availability, experimental reefs were made with identical numbers and sizes of rocks. Each reef consisted of 32 rocks that ranged in length from 5 to $30 \mathrm{~cm}$. The number of rocks per reef was doubled for Experiment 3 to ensure that predators could not eat all of the gobies on reefs exposed to predation. The experimental reefs mimicked areas of rock rubble that are commonly encountered in nature; in this rubble microhabitat Lythrypnus and Coryphopterus commonly co-occur as the numerically dominant resident fishes. All reefs in the first two experiments were constructed inside cages, $1 \times 1 \times 0.67 \mathrm{~m}$ high, made of polyvinyl chloride pipe frames and covered on all sides by $19-\mathrm{mm}$ mesh rigid plastic netting. However, in Experiment 3 some of the reefs were not inside these cages, so I could explore effects of predators. The 19-mm mesh did not restrict movement of gobies onto or off reefs, but it excluded all predators $>80-\mathrm{mm}$ SL. Scuba divers cleaned fouling organisms off the cages approximately twice a week. To account for spatial variation among replicate reefs, the experimental reefs were placed in three rows at 10,20, and $30 \mathrm{~m}$ from the edge of a large rocky reef that ran parallel to shore (Fig. 1). Depth increased with distance from the edge of the reef: the average depth of reefs in each of the three rows was 7,9 , and $11 \mathrm{~m}$; within rows, reefs varied in depth $<3$ $\mathrm{m}$. Since I have not seen either goby species $>1 \mathrm{~m}$ away from rocks, I attempted to minimize exchange of gobies among reefs by separating adjacent reefs by 10 $m$ of sand.

Treatments consisted of five (Experiment 3) or six (Experiments 1 and 2) combinations of three densities (zero, ambient, and twice ambient) of each of the two gobies, and in Experiment 3 these treatments were crossed with two levels of predation (for the specific treatments, see the following three subsections). While I would have preferred to use a fully orthogonal set of density treatments (nine instead of five or six), the logistics involved in capturing and tattooing that many gobies precluded use of such a design in all three experiments. I included one replicate of each treatment in each of the three rows of reefs. Within each row, treatments were assigned randomly, with the additional requirement that identical treatments in different rows could not be adjacent. Reefs designated to receive gobies were stocked with a standard size distribution of individuals particular to each species. All fish added to the reefs were measured and then marked subcutaneously with an acrylic paint tattoo that indicated their standard length (to the nearest $\mathrm{mm}$ ). The size distributions of fish stocked on the reefs were representative of those in natural populations, except that no fish smaller than 16-mm SL were used because they were too difficult to mark without causing high mortality. The Coryphopterus I used ranged from 21 to $85 \mathrm{~mm}$ $\mathrm{SL}$, and the Lythrypnus ranged from 16 to $36 \mathrm{~mm} \mathrm{SL}$. At least twice weekly throughout each experiment, divers recorded the numbers of recruits and postrecruits (distinguished by size) of each species seen during 5-min periods at each reef. After $3.5 \mathrm{wk}$, divers collected all of the gobies on each reef. (The two gobies accounted for $\approx 99 \%$ of all resident fishes collected from the reefs.) I measured recruitment as the number of individuals collected at $3.5 \mathrm{wk}$ that lacked acrylic tattoos and that were too small to be immigrants from other reefs. To determine the maximum size cutoff for recruits, I added the maximum observed growth rate for the species (11 and $12 \mathrm{~mm}$ over $3.5 \mathrm{wk}$ for Lythrypnus and Coryphopterus, respectively) to the approximate average size of each species at settlement 
(10 and $20 \mathrm{~mm}$ for Lythrypnus and Coryphopterus, respectively). Hence, I classified as recruits Lythrypnus $\leq 21 \mathrm{~mm}$ and Coryphopterus $\leq 32 \mathrm{~mm}$. With this method, individuals that settled at relatively large sizes and grew rapidly would have been classified as immigrants, but since few individuals were near the size cutoffs, this bias was probably slight. Also, I would have considered individuals that migrated onto the experimental reefs after settlement, but at a small size, to be recruits, thereby confounding recruitment with immigration. This too was probably an unimportant bias since there was little evidence that the gobies could successfully move among reefs: $<1 \%$ of the tattooed gobies successfully moved between reefs, and smaller individuals, such as the recruits, appear to be even more site attached than larger fish (M. A. Steele, personal observation). Since I measured recruitment after $3.5 \mathrm{wk}$, the density of recruits was potentially affected by presettlement, settlement, and early postsettlement processes. Over the 3.5-wk duration of each experiment, reef-based processes other than the three that I explored (predation, intra- and interspecific interactions) may also have affected recruitment, but I confine my evaluation of the importance of reef-based processes to those few processes that I investigated; because of this, I probably underestimate the overall importance of reef-based processes relative to pre-settlement processes.

I aimed to use densities of resident gobies that reflected the means, and fell within the ranges of densities naturally experienced by the two species. I used combinations of three densities of each species (zero, "ambient," and twice ambient). For each species, I determined ambient density by censusing $1-\mathrm{m}^{2}$ quadrats in microhabitats that were qualitatively "good" for the species of interest. Since I was interested in interactions between recruits and residents, and because these interactions can occur only in areas where residents are present, to determine the ambient density of conspecifics that a recruit might encounter, I sampled only in areas where at least one resident was present. Ambient density was calculated as the average of mean densities on three reefs (10-30 haphazardly selected quadrats per reef). During 1992, I estimated the average density of Lythrypnus per square meter to be $20.0 \pm 2.2$ (mean $\pm 1 \mathrm{SE}, n=3$ reefs for each species in each month) in July, $35.6 \pm 9.5$ in August, and $35.9 \pm 13.3$ in September. The mean estimated densities of Coryphopterus for these same months were $3.0 \pm 0.2,3.3 \pm$ 0.4 , and $2.5 \pm 0.5$, respectively. I expected that all densities were somewhat underestimated because these species often hide in crevices or under rocks, and hence, cannot be counted without destructive sampling. While the extent to which visual censuses underestimate true densities will be dependent on microhabitat type, by comparing visual counts with destructive sampling on $361-\mathrm{m}^{2}$ artificial reefs, I found that true densities of Lythrypnus were $\approx 1.5$ times greater than visual counts indicated and that true densities of Coryphopterus were $\approx 1.8$ times greater than indicated by visual counts.

Experiment 1: Effects on recruitment under a low ambient density regime.-I designed this experiment to test for effects of resident Lythrypnus and resident Coryphopterus on recruitment of the two gobies, in the absence of predators. I used six treatments: (1) ambient density Lythrypnus, (2) double ambient density Lythrypnus, (3) ambient density Lythrypnus + ambient density Coryphopterus, (4) ambient density Coryphopterus, (5) double ambient density Coryphopterus, and (6) zero resident density. Each of the six treatments was represented once in each row of reefs (3 rows, 18 reefs total). I used 20 Lythrypnus, and 5 Coryphopterus, per square meter to represent ambient densities. Thus, appropriate reefs were stocked with 0,20 , or 40 tattooed Lythrypnus, and 0, 5, or 10 tattooed Coryphopterus.

Experiment 2: Effects on recruitment under a high ambient density regime.-This experiment employed the same design as Experiment 1, but higher densities of gobies were used. I increased the ambient density of Lythrypnus to 30 individuals $/ \mathrm{m}^{2}$ to reflect seasonal changes on natural reefs where densities had increased to $35.6 \pm 9.5$ ( $n=3$ reefs). For Coryphopterus, I increased ambient density to 15 individuals $/ \mathrm{m}^{2}$ for three reasons: (1) High and variable loss (mortality + emigration) of tattooed Coryphopterus from reefs in the first experiment resulted in low resident densities, which did not always differ among density treatments. By increasing the numbers stocked I hoped that more fish would remain on the reefs throughout the experiment. (2) An average of $18.8 \pm 1.8$ (maximum $=36$; $n=18$ ) Coryphopterus (including recruits) were collected per $1-\mathrm{m}^{2}$ reef at the end of Experiment 1, indicating that densities could reach much higher levels than I had previously observed. (3) No effects of this species were noted in the first experiment (see Results), so I increased the range of densities to make a stronger test for effects by resident Coryphopterus. Also, Coryphopterus were restocked weekly (with other tattooed individuals) in an effort to maintain differences among treatments. The restocking of lost individuals, combined with the use of greater ambient densities than in Experiment 1, did maintain higher densities of $\mathrm{Co}$ ryphopterus in this experiment than in the other two; as such, it should have provided a stronger test for effects of this species on recruitment of the two gobies.

Experiment 3: Effects of resident gobies and predators on recruitment.-In this experiment I manipulated three factors: the density of resident Lythrypnus, the density of resident Coryphopterus, and the presence of predators. Hence, I could test for effects on recruitment of either goby species caused by: resident Lythrypnus, resident Coryphopterus, predator presence, and any interactions among these factors. I used 11 treatments to explore these issues. Five of the six goby density combinations used in the previous experiments 
were employed: (1) ambient density Lythrypnus, (2) double ambient density Lythrypnus, (3) ambient density Lythrypnus plus ambient density Coryphopterus, (4) ambient density Coryphopterus, and (5) zero resident density. The double ambient density Coryphopterus treatment was omitted for logistical reasons and because the previous experiments had not demonstrated any consistent effects of this species on recruitment of either goby (see Results). I used the same ambient densities as in Experiment 2, but neither species was restocked during the experiment. The five density combinations were established on reefs that were enclosed in complete cages and on reefs enclosed in open cages, resulting in ten treatments. I used open cages (cages that lacked netting on the lower half of one side) instead of completely uncaged reefs to minimize differences caused by "cage effects." Since the structure of open cages was virtually identical to that of the complete cages (open cages lacked only $9 \%$ of the netting used on the complete cages) it seemed unlikely that cage effects on the gobies would confound tests for predator effects. However, because the open cages severely limited access of reefs to predators, I expected them to underestimate the magnitude of any predator effect. I added an additional treatment to aid in assessing cage artifacts: it consisted of reefs with no cage at all, and no resident gobies added. Recruitment to these uncaged, zero resident density reefs was compared to that on partially caged and completely caged, zero resident density reefs to test for cage artifacts.

In all, I used 36 rock rubble reefs (18 additional reefs were added onto the ends of the original rows). Within each row of 12 reefs, each treatment was represented once, except the control (no cage, no residents added) of which there were two per row because this treatment required minimal effort to establish. In this experiment only, in addition to counting gobies at least twice weekly, divers also recorded the maximum number of predatory fishes present within $1 \mathrm{~m}$ of each reef at any time during the standard 5-min goby counting period. I compared patterns of predator abundance among rows and among caging treatments. All other methods used were the same as described for the previous experiments.

Analysis of experiments.-I tested the effects on recruitment by resident gobies, predators, and spatial location ("row" and "position" effects) with analysis of covariance (ANCOVA). I used as covariates the densities of residents of each species of goby in models with predator exposure (Experiment 3 only) and row treated as fixed categorical effects. I considered row to be a fixed effect because the locations of the rows of reefs were chosen systematically (not randomly) along gradients in both depth and distance from the nearby natural reef; also, I expected that there might be predictable differences in recruitment across the depth/ distance gradient and I wanted to compare the magnitude of differences in recruitment amongst the rows of reefs. Position (the position of a reef relative to the mouth of the cove) was included as a covariate. For the analyses of Experiment 3, I included only reefs that were enclosed in complete or open cages, to avoid confounding predator effects with cage effects; the completely uncaged reefs were used only in tests of cage effects.

Because loss rates (mortality + emigration) of stocked gobies varied among the reefs, differences among density treatments were not always well maintained. To conduct the most accurate tests for effects of resident gobies on recruitment, rather than treat resident goby density as a categorical factor, I used, as covariates, estimates of the average density of residents on each reef. To calculate the mean density of postrecruit residents (both marked individuals and immigrants) on a reef, I estimated the density of gobies residing on that reef for every day of the experiment and averaged this over the duration of the experiment; the daily densities I estimated from density trajectories based on the frequent counts made by divers.

I examined the parametric assumptions of normality and homogeneity of variances by inspecting normal probability plots and regressions of residuals vs. estimates of recruitment from ANCOVA models. Numbers of recruits/reef were square root $(x+0.5)$ transformed to meet the assumptions where necessary. Since numbers of Coryphopterus recruits in Experiment 2 could not be transformed to meet the assumption of normality, the results of this analysis should be interpreted cautiously. Interactions among covariates were not tested: in the case of the interaction between resident densities of each species this would have been inappropriate because the design of the experiment was not fully orthogonal with regard to goby density (no treatments were included with high densities of both species). I tested for interactions between intra- and interspecific effects by analyzing the subset of the treatments for which density treatments were fully orthogonal (i.e., zero resident density, ambient Lythrypnus, ambient Coryphopterus, and ambient Lythrypnus + ambient Coryphopterus). For all ANCOVAs, I tested the assumption of homogeneity of slopes by first constructing a "complete" model that included all possible interactions between covariates and the categorical effects row and "predator exposure" (Experiment 3 only), and I then sequentially eliminated all those interactions that were not significant $(P>0.05)$. Interaction terms could only be removed from the model if higher order interactions involving them had already been eliminated. The covariate position was also eliminated using this procedure if it was not significant.

I evaluated quantitatively the relative importance of the various factors that affected recruitment of the gobies in two ways: by comparing variance components, and by comparing the magnitude of effects relative to the mean ("intensity"). Variance components analysis (Winer et al. 1991, Underwood and Petraitis 
1994) reveals how much of the total variation within each experiment was accounted for by each factor (based on $\omega^{2}$ ) in the ANCOVA models. The intensity of a factor simply indicates the size of the effect it caused relative to the mean; hence, this measure ignores any variability in the effect of the factor. I expressed intensity as percent change relative to mean recruitment. The intensity of predation, the effects of conspecifics, and the effects of heterospecifics, then, were calculated as:

$$
\frac{F_{p}-F_{a}}{\bar{X}_{c}} \times 100
$$

where $F_{p}$ is the mean recruitment on reefs exposed to the factor of interest (i.e., predators, conspecific residents, or heterospecific residents), $F_{a}$ is the mean recruitment to reefs not exposed to the particular factor (i.e., reefs with no predators, no conspecifics, or no heterospecific residents), and $\bar{X}_{c}$ is the mean recruitment to all reefs in complete cages. In both Experiments 1 and $2, \bar{X}_{c}$ was the grand mean, since all reefs were enclosed in cages, but $\bar{X}_{c}$ was not the grand mean in Experiment 3 (because half of the reefs were not in complete cages). I used $\bar{X}_{c}$ rather than the grand mean in Experiment 3 to allow the intensity of effects to be readily compared among the three experiments. To remove effects of other factors, $F_{p}$ and $F_{a}$ were adjusted least squares (LS) means from final ANCOVA models, which were backtransformed. To estimate the intensity of the effects by resident gobies, adjusted Ls means were calculated from ANCOVA models that treated resident goby densities as categorical factors (present $\left[F_{p}\right]$, or absent $\left.\left[F_{a}\right]\right)$.

I found that the spatial location of the reefs affected recruitment (see Results); I calculated the intensity of the effects of reef location as:

$$
\frac{R_{\max }-R_{\min }}{\bar{X}_{c}} \times 100
$$

where $R_{\max }$ was the expected number of recruits on the reef (or row of reefs) in the location predicted to receive the most recruits and $R_{\min }$ was the expected number of recruits in the location predicted to receive the fewest recruits. For example, recruitment generally declined from the 30-m row of reefs to the $10-\mathrm{m}$ row of reefs. In that scenario, I used the mean recruitment to the 30-m row as $R_{\max }$ and the mean recruitment to the $10-\mathrm{m}$ row as $R_{\min }$. Again, the effects of other factors were removed by using adjusted LS means from final ANCOVA models. In experiments where I detected both row and position effects, calculating $R_{\max }$ and $R_{\min }$ was more involved: in these cases, I used both adjusted LS means for the row effect and the slope of the relationship between position and recruitment to calculate the number of recruits expected on the reef in the best $\left(R_{\max }\right)$ and in the worst $\left(R_{\min }\right)$ location.

\section{Occurrence of recruits and older conspecifics on natural reefs}

I also investigated the relationship between the density of recruits and the density of older conspecifics on natural reefs, for both goby species. Recruits and postrecruits were counted in haphazardly placed $1-\mathrm{m}^{2}$ quadrats. Recruits and postrecruits were defined by size: Coryphopterus $\leq 30 \mathrm{~mm}$ SL (individuals that had settled within $\approx 1 \mathrm{mo}$ ) and Lythrypnus $<15 \mathrm{~mm}$ SL (individuals that had settled within $\approx 2$ wk) were considered to be recruits. Coryphopterus were surveyed in July, August, and September 1992 at three reefs by the same observer ( $n=10$ quadrats $\left.\cdot \mathrm{reef}^{-1} \cdot \mathrm{mo}^{-1}\right)$. Three divers gathered all of the data for Lythrypnus on 6 September 1992 at five reefs, along one to three depth strata per reef $(3,6$, or $9 \mathrm{~m} ; n=10$ quadrats. stratum $^{-1} \cdot$ reef $\left.^{-1}\right)$.

Relationships between recruit density and the density of older conspecifics were evaluated by using ANCOVA to reduce unexplained variance in recruit density that could be attributed to categorical factors such as differences among reefs, months, depths, and observers. For Lythrypnus, I analyzed the data collected from the five reefs with four ANCOVAs. I did separate analyses for each of three reefs because, on these reefs, potential observer bias was confounded with depth effects (i.e., there were different observers at different depths on different reefs); these ANCOVAs included the continuous variable "postrecruit density" and the categorical effect "observer/depth." I included the remaining two reefs in one analysis because they were sampled by the same individual and hence, the counts of fish on these reefs were not subject to observer bias; this analysis included the categorical variable "reef" and the continuous variable postrecruit density. For each of the four ANCOVAs, numbers of Lythrypnus recruits were $\ln (x+1)$ transformed to meet the assumption of homoscedasticity, and for the three analyses conducted on individual reefs, I also transformed the density of postrecruit Lythrypnus to $\ln (x+1)$ to create a linear relationship between recruit and postrecruit density. For Coryphopterus, I also used an ANCOVA to test for a relationship between recruit and postrecruit density; again, density of postrecruits was a continuous variable and I included two categorical effects, "month" and reef, to reduce unexplained variance. I used a mixed model in which reef was a random factor and month a fixed factor since levels of this variable may correspond to predictable seasonal variation in recruitment. Data for Coryphopterus could not be transformed to meet the assumption of normality, so this analysis should be interpreted cautiously. For both species, the assumption of homogeneity of slopes was tested as previously described for the analyses of the experiments. 
TABLE 1. Average recruitment to rows of reefs constructed at three distances $(10,20$, or 30 m) from a large continuous rocky reef (see Fig. 1).

\begin{tabular}{lccccccc}
\hline \hline & \multicolumn{3}{c}{ Lythrypnus } & & \multicolumn{3}{c}{ Coryphopterus } \\
\cline { 2 - 3 } \cline { 6 - 8 } Row & Exp. 1 & Exp. 2 & Exp. 3 & & Exp. 1 & Exp. 2 & Exp. 3 \\
\hline $10 \mathrm{~m}$ & $5.3 \pm 0.8$ & $3.2 \pm 1.0$ & $13.2 \pm 2.2$ & & $11.6 \pm 2.2$ & $1.0 \pm 0.9$ & $1.2 \pm 0.5$ \\
$20 \mathrm{~m}$ & $7.2 \pm 0.9$ & $11.3 \pm 1.8$ & $18.8 \pm 2.4$ & & $15.8 \pm 2.5$ & $2.9 \pm 1.2$ & $1.8 \pm 0.4$ \\
$30 \mathrm{~m}$ & $8.6 \pm 0.9$ & $17.6 \pm 2.3$ & $23.2 \pm 4.3$ & & $14.0 \pm 2.3$ & $5.3 \pm 1.6$ & $3.0 \pm 0.5$ \\
\hline
\end{tabular}

Notes: Among rows, depth increased with distance from the continuous reef. Data are backtransformed adjusted LS means ( $\pm 1 \mathrm{SE}$ ) from final ANCOVA models. $n=6,6$, and 10 reefs per row for Experiments 1, 2, and 3, respectively.

\section{RESUlts}

\section{Effects of spatial location}

Recruitment of Lythrypnus was always greatest on the deepest, most offshore reefs, and declined with proximity to the nearby large reef (Table 1). These effects of reef location were indicated by significant row effects in ANCOVA models for every experiment (Table 2). The same spatial pattern of recruitment was present in two of three experiments for Coryphopterus (Table 1); differences among rows of reefs were not significant in one experiment, marginally significant in another, and highly significant in the third (Table 3 ). For Lythrypnus, I also detected a second spatial pattern in recruitment; recruitment increased with proximity to the mouth of the cove (Position; Table 2, Fig. 2) in the first two experiments, but not in the third. I found no such pattern in the recruitment of Coryphopterus (the covariate position did not explain a significant fraction of the variation in the ANCOVA models for any of the three experiments and, hence, was eliminated from them).

\section{Intraspecific effects}

In all three experiments, the number of Lythrypnus that recruited to a reef was positively related to the number of older conspecifics residing there (Table 2, Fig. 3). On predator-free reefs, this facilitation by residents resulted in 1.37-1.46 times as many individuals recruiting to reefs stocked with older Lythrypnus as to reefs where none were stocked (based on backtransformed adjusted LS means from ANCOVA models, which treated resident density as a categorical factor: present or absent; Fig. 4). On predator-exposed reefs (Experiment 3), only 1.10 times as many Lythrypnus recruited to reefs stocked with conspecifics as to those without. Although the average gain of recruits due to facilitation was lower in the presence of predators (Fig. 4), the response of recruits to residents was the same (i.e., the slopes of the relationships between recruit density and conspecific resident density for predatorexposed and predator-free reefs did not differ: there was a nonsignificant resident Lythrypnus $\times$ predator exposure interaction term; Fig. 5). On natural reefs the

TABLE 2. Results of analyses of covariance for effects on recruitment of Lythrypnus. Data are numbers of recruits/reef, square root $(x+0.5)$ transformed.

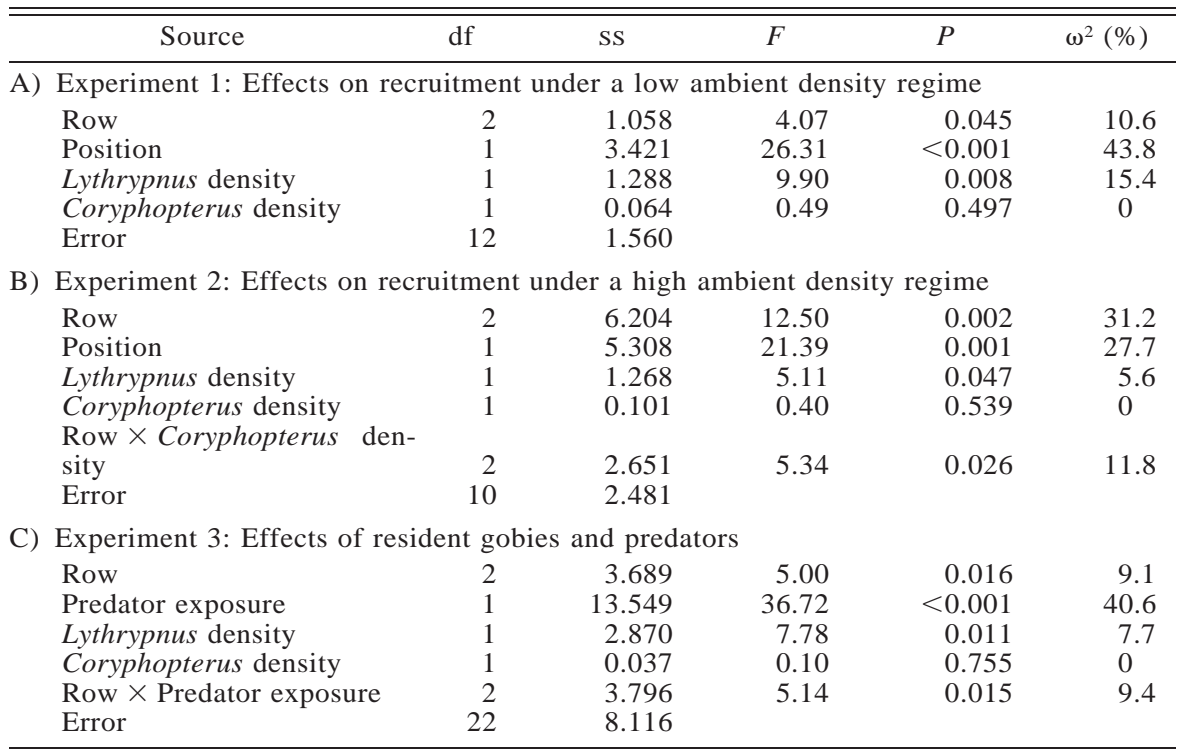


TABLE 3. Results of analyses of covariance for effects on recruitment of Coryphopterus. Data are numbers of recruits/reef, square root $(x+0.5)$ transformed.

\begin{tabular}{lccccc}
\hline \hline \multicolumn{1}{c}{ Source } & $\mathrm{df}$ & $\mathrm{ss}$ & $F$ & $P$ & $\omega^{2}(\%)$ \\
\hline A) Experiment 1: Effects on recruitment & under & a low & ambient density & regime & \\
Row & 2 & 0.838 & 0.83 & 0.458 & 0 \\
Lythrypnus density & 1 & 0.463 & 0.92 & 0.355 & 0 \\
Coryphopterus density & 1 & 0.279 & 0.55 & 0.470 & 0 \\
Error & 13 & 6.554 & & & \\
B) Experiment 2: Effects on recruitment under a high ambient density regime & \\
Row & 2 & 4.219 & 3.61 & 0.056 & 20.6 \\
Lythrypnus density & 1 & 2.156 & 3.69 & 0.077 & 10.6 \\
Coryphopterus density & 1 & 0.225 & 0.38 & 0.545 & 0 \\
Error & 13 & 7.592 & & & \\
C) Experiment 3: Effects of resident gobies and predators & & & \\
Row & 2 & 2.872 & 10.84 & 0.001 & 25.6 \\
Predator exposure & 1 & 0.002 & 0.01 & 0.913 & 0 \\
Lythrypnus density & 1 & 0.007 & 0.05 & 0.819 & 0 \\
Coryphopterus density & 1 & 1.688 & 12.75 & 0.002 & 15.3 \\
Row X Predator exposure & 2 & 1.234 & 4.66 & 0.022 & 9.5 \\
Row X Coryphopterus density & 2 & 1.606 & 6.06 & 0.009 & 13.2 \\
Error & 20 & 2.649 & & & \\
\hline
\end{tabular}

density of Lythrypnus recruits was also positively related to density of older resident conspecifics (Fig. 6a; ANCOVAs: reefs BFC Back and BFC South, $F_{1,17}=$ 7.27, $P=0.015$, Bird Rock, $F_{1,26}=6.87, P \ll 0.001$, Pumpernickel Cove, $F_{1,26}=4.54, P<0.001$, BFC North, $\left.F_{1,17}=6.75, P \ll 0.001\right)$.

Recruitment of Coryphopterus was not consistently related to the density of conspecifics. Only in Exper-

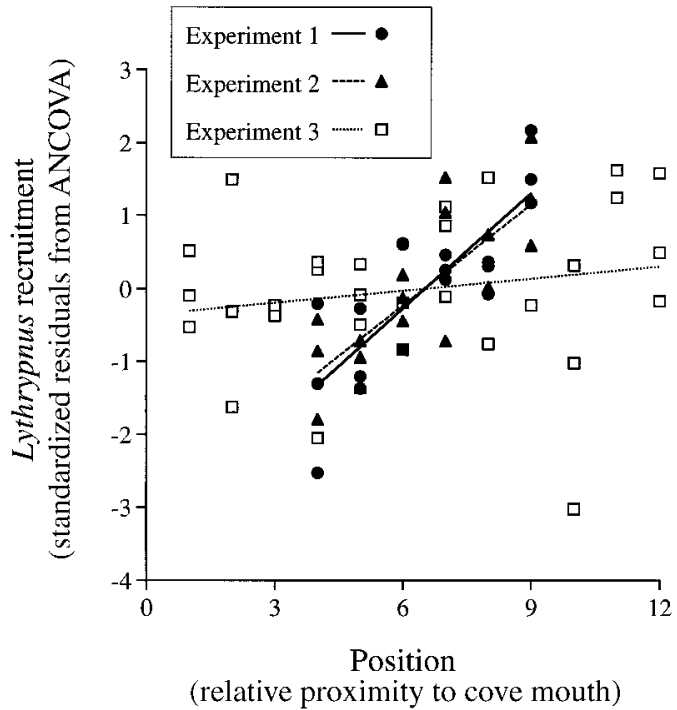

FIG. 2. Relationships between recruitment of Lythrypnus and reef position relative to the mouth of the cove. Larger position values are nearer to the cove mouth. Recruitment of Lythrypnus is expressed as standardized residuals from final ANCOVA models that excluded position. Linear relationships were statistically significant for Experiments 1 and 2, but not 3. Slopes of the linear relationships do not differ between Experiments 1 and 2, both differed from Experiment 3 , based on ANCOVA. For Experiments 1, 2, and 3, $n=18$, 18 , and 30 , respectively. iment 3 did I detect any effects of conspecifics, but the effects differed between rows (i.e., a significant row $\times$ resident Coryphopterus interaction; Table 3): in two rows, the density of resident Coryphopterus positively affected recruitment of conspecifics, but in the third row there was no such relationship (Fig. 7). The inconsistency of the effects of conspecifics on recruitment of Coryphopterus is further highlighted by the lack of any significant relationship between the density

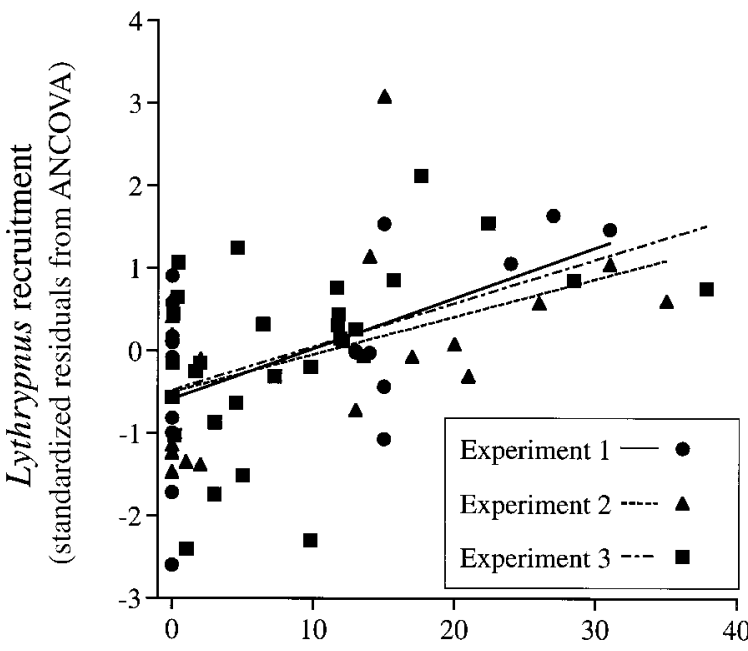

Density of resident stocked Lythrypnus (no. $/ \mathrm{m}^{2}$ reef)

FIG. 3. Relationships between recruitment of Lythrypnus and density of stocked Lythrypnus on experimental reefs. Recruitment of Lythrypnus is expressed as standardized residuals from final ANCOVA models that do not include stocked Lythrypnus density. Slopes of linear relationships do not differ between experiments, based on ANCOVA. For Experiments 1,2 , and $3, n=18,18$, and 30 , respectively. 


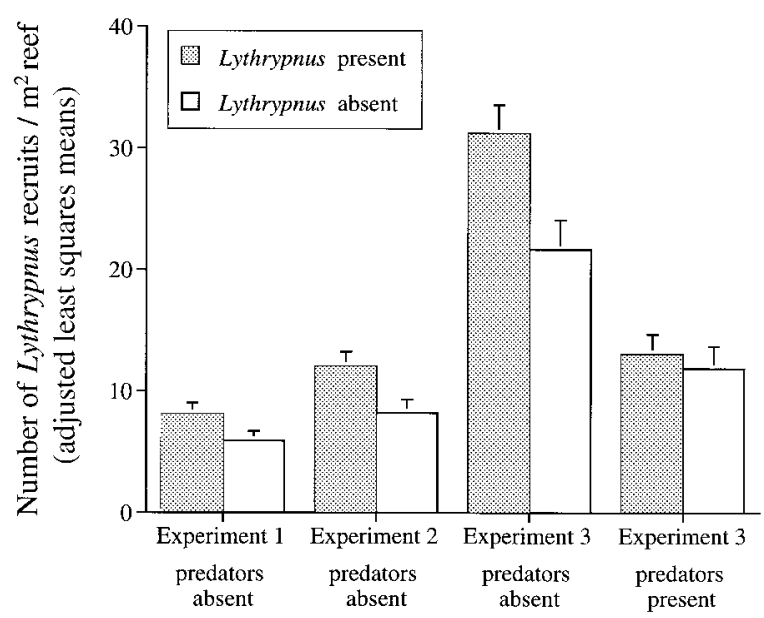

FIG. 4. Recruitment of Lythrypnus to reefs stocked with Lythrypnus and to those not stocked with conspecifics. Recruitment is calculated as backtransformed adjusted LS means (of numbers of individuals per reef) from final ANCOVA models with Lythrypnus density treated as a categorical effect, instead of as covariate as was done to test for effects. Error bars are pooled SE from ANCOVA. For each bar $n=9$, except for Experiment 3, where $n=6$ for each bar where Lythrypnus were absent.

of recruits and the density of older residents on natural reefs $\left(F_{1,80}=1.78, P=0.19\right)$. If anything, the data from natural reefs suggest a negative effect of resident conspecifics on recruitment (Fig. 6b).

\section{Interspecific effects}

I found no consistent evidence of interspecific effects. In two experiments (Experiment 1 and 3) there was no evidence of negative effects by one species on the other (Tables 2 and 3). In Experiment 2 (the experiment that should have produced the strongest tests for effects by Coryphopterus, since higher densities of this species were maintained by restocking) recruitment of Lythrypnus was negatively related to the density of resident Coryphopterus in two rows, but positively related in the third row (Fig. 8). This resulted in a significant statistical interaction between row and resident Coryphopterus density (Table 2B). Inter- and intraspecific effects did not interact in any experiment (Lythrypnus density $\times$ Coryphopterus density interaction: Experiment $1, F_{1,5}=0.40, P=0.56$; Experiment 2, $F_{1,5}=0.72, P=0.44$; Experiment $3, F_{1,12}=2.67, P$ $=0.13)$.

\section{Effects of predators}

Predators had strong effects on recruitment of Lythrypnus: over twice as many recruits were collected from completely caged reefs ( - predators) as from reefs in open cages $(+$ predators) (number of recruits $=27.9$ \pm 2.6 [mean $\pm 1 \mathrm{SE}$ ] on reefs in complete cages, and $13.1 \pm 1.3$ on reefs in open cages, $n=15)$. There was scant evidence, however, of an effect by predators on

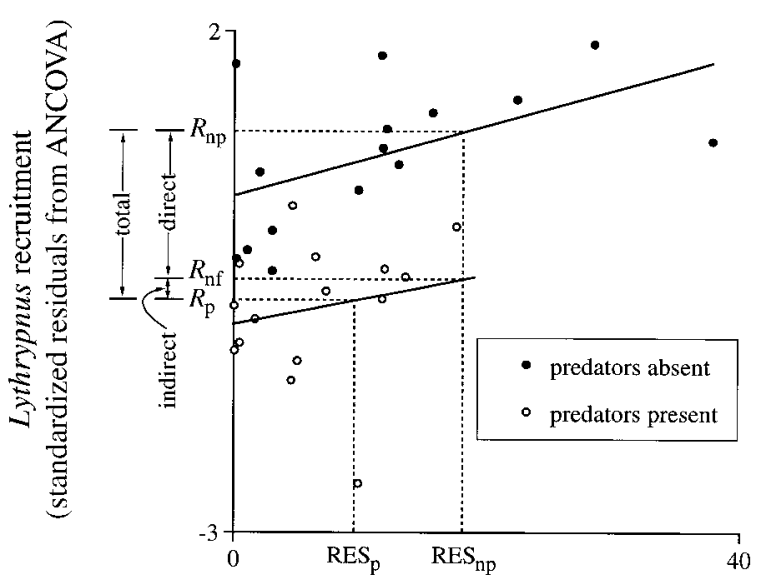
Density of resident stocked Lythrypnus
(no./ $/ \mathrm{m}^{2}$ reef)

FIG. 5. Relationships between recruitment $(R)$ of Lythrypnus and density of resident Lythrypnus that were stocked on reefs in Experiment 3. One half of the reefs were exposed to predators, the other reefs were not. Recruitment of Lythrypnus is expressed as standardized residuals from the ANCOVA model in Table $2 \mathrm{C}$, after excluding the terms resident Lythrypnus density and predator exposure. Slopes of the two lines do not differ (based on ANCOVA). The mean density of stocked conspecifics residing on predator-free reefs is represented by $\mathrm{RES}_{\mathrm{np}}$; predators reduced the mean density of residents to $\mathrm{RES}_{\mathrm{p}}$ on predator-exposed reefs. The total effect of predators on recruitment of Lythrypnus is the difference between $R_{\mathrm{np}}$ and $R_{\mathrm{p}}$. The indirect effect of predators on recruitment, caused by reducing the density of resident conspecifics, is the difference between $R_{\mathrm{nf}}$ and $R_{\mathrm{p}}$. For each of the two predation treatments $n=15$.

recruitment of Coryphopterus: on average $2.2 \pm 0.5$ recruits were collected on completely caged reefs vs. $1.9 \pm 0.5$ on reefs in open cages $(n=15)$. One aspect of predation common to both species was that the effects of predators varied among rows of reefs (as indicated by significant predator exposure $\times$ row interaction terms in ANCOVAs; Tables 2C and 3C). For Lythrypnus, the effects of predators varied only in magnitude, while the effects of predators on Coryphopterus varied both in magnitude and direction, being positive in one row and negative in the other two rows of reefs (Fig. 9). The greatest reductions in recruitment occurred in the row of reefs that was deepest and most offshore (the 30-m row; Fig. 9). These patterns of variation in the effects of predators would be expected if predators were most abundant where their effects were strongest, but this was not the case; predators, both known (kelp and barred sand basses) and potential (the wrasses: sheephead, rock wrasse, and señorita), were at or near their lowest abundances in the 30-m row, where predation was strongest, and reached their highest abundances in the 10-m row, where predation was weak (mean number of basses within $1 \mathrm{~m}$ of reefs \pm $1 \mathrm{SE}=2.8 \pm 0.5,1.0 \pm 0.3$, and $0.95 \pm 0.2$ for 10 -, 


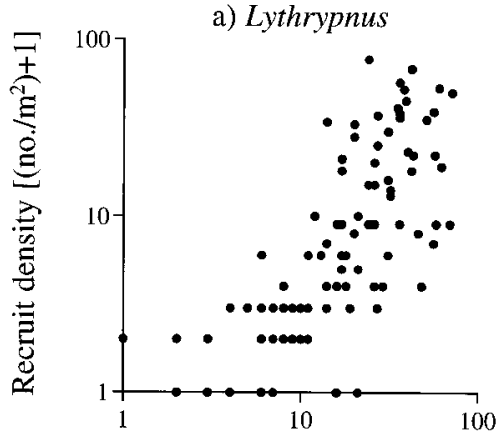

Conspecific postrecruit density $\left[\left(\right.\right.$ no. $\left.\left./ m^{2}\right)+1\right]$

b) Coryphopterus

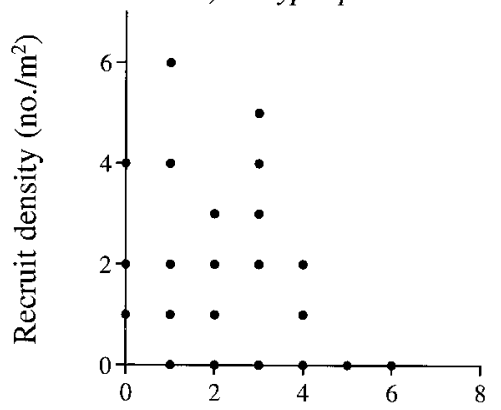

Conspecific postrecruit density $\left(\right.$ no. $\left./ \mathrm{m}^{2}\right)$

FIG. 6. Relationships between recruit and postrecruit density on natural reefs for both species. For each species, data from all reefs and dates are pooled. For Coryphopterus and Lythrypnus, $n=90$ and 100, respectively.

$20-$, and 30-m rows of reefs, respectively [ $n=12$ reefs/ row]; mean number of wrasses $=2.1 \pm 0.4,0.6 \pm 0.1$, $0.7 \pm 0.1$ for the rows in the same order). These differences in predator abundance among rows were statistically significant (one-factor ANOVA for differences among rows: $F_{2,33}=9.10, P<0.001$ for basses and $F_{2,33}=12.7, P<0.0001$ for wrasses; for both the basses and the wrasses, abundance was significantly greater in the $10-\mathrm{m}$ row than the 20 - and $30-\mathrm{m}$ rows, which did not differ, based on post hoc Tukey HSD tests).

I found no statistical evidence indicating that predator effects were confounded with cage artifacts. Recruitment of Lythrypnus did not differ significantly between reefs in open cages ( + predators) and uncaged reefs ( + predators) (Tukey HSD test, $P=0.46$, Fig. 10a). Recruitment of Coryphopterus did not differ among any of the three predator exposure treatments (ANOVA, $F_{2,7}=3.05, P=0.11$; Fig. $10 \mathrm{~b}$ ). There was, however, a suggestion of a negative effect of cages on recruitment of Coryphopterus (compare the open cage to the no cage treatment in Fig. 10b). Such an effect would not confound cage effects with predator effects

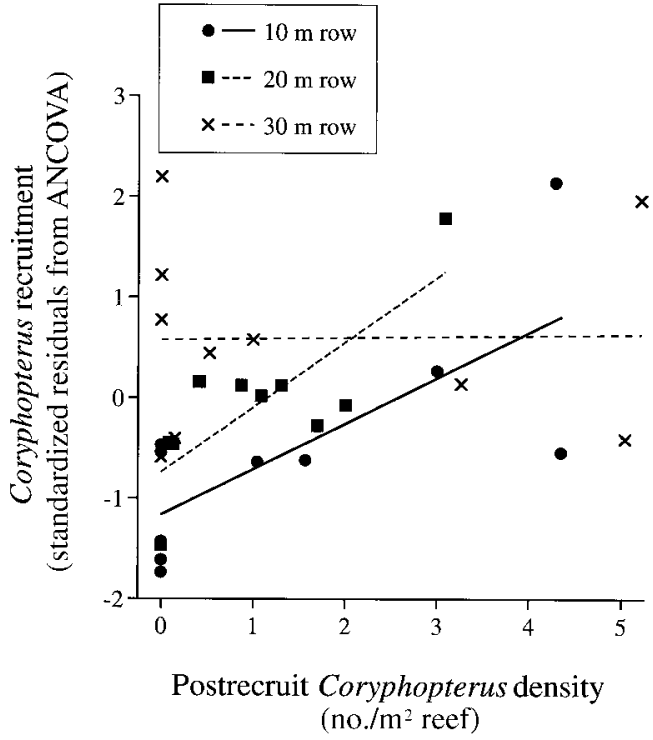

FIG. 7. Relationships between recruitment of Coryphopterus and density of postrecruit conspecifics for each row of reefs in Experiment 3. Recruitment of Coryphopterus is expressed as standardized residuals from the final ANCOVA model after excluding the terms row and postrecruit Coryphopterus density, and any interactions involving them. For each row of reefs, $n=10$.

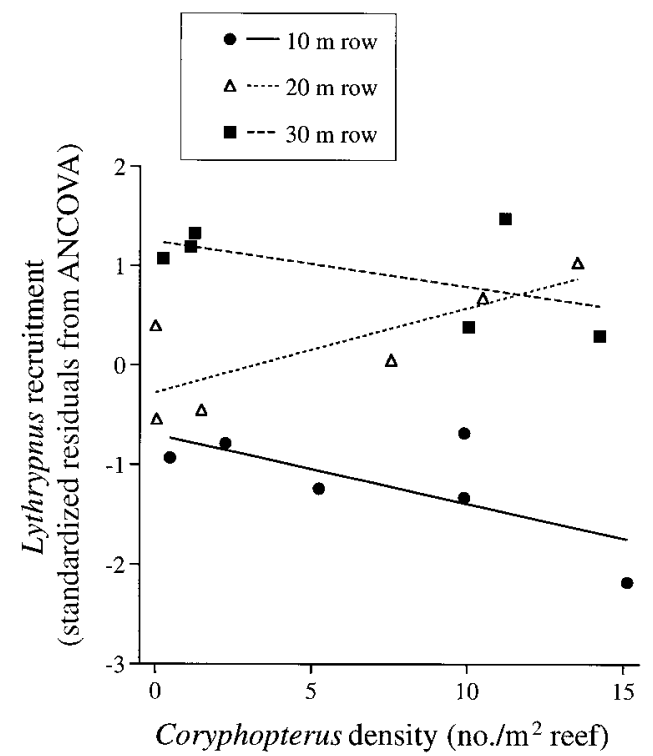

FIG. 8. Recruitment of Lythrypnus related to postrecruit Coryphopterus density by row in Experiment 2. Recruitment of Lythrypnus is expressed as residuals from the final ANCOVA model after excluding row, Coryphopterus density, and their interaction. For each row of reefs, $n=6$. 


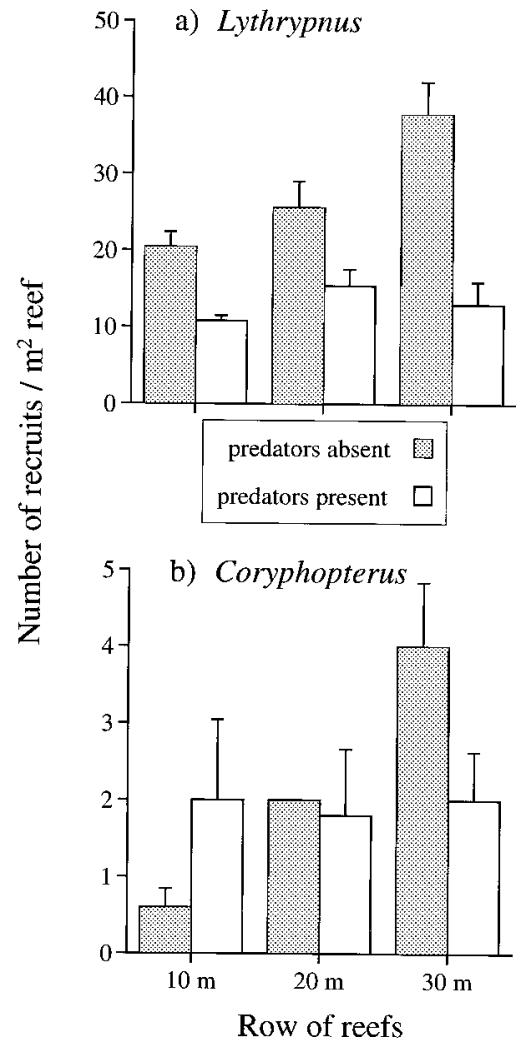

FIG. 9. Effects of predators on recruitment of both gobies, for each row of reefs, in Experiment 3. Data are means \pm 1 $\mathrm{SE}, n=5$. There was no error about the mean for Coryphopterus, in the 20-m row, on predator-free reefs (two recruits were collected from each of the five reefs).

(that is, if predator effects are tested by comparing caged reefs to reefs in open cages), rather, the lower overall densities of recruits would reduce the power of statistical tests to detect differences between the treatments. Hence, my tests for predator effects on $\mathrm{Co}$ ryphopterus may have been weakened by a negative effect of cages on recruitment of this species. Another potential problem was that some completely caged reefs ("predator-free" reefs) were invaded by small kelp bass $(<80 \mathrm{~mm} \mathrm{SL})$. These bass subsequently took up residence for varying periods of time. Three out of five caged reefs were invaded by $1-4$ bass/cage in each of the 10- and 20-m rows of reefs, but no caged reefs were invaded in the 30-m row. Had these small bass reduced recruitment on the caged reefs where they resided, it would have been more difficult to detect a predator effect since the difference between completely caged reefs ( - predators) and reefs in open cages $(+$ predators) would have been reduced. Apparently, however, these small bass had no effect on recruitment of either species: ANCOVA (including the factor resident bass abundance, at two levels: present or absent, and other variables that significantly affected recruitment

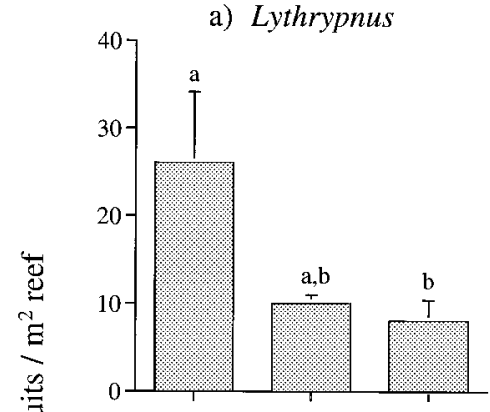

b) Coryphopterus

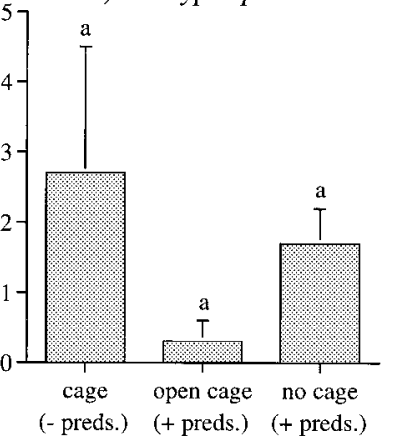

Predator exposure treatment

FIG. 10. Recruitment of both species to different predator exposure treatments in Experiment 3. Only reefs not stocked with gobies (zero density treatment) were included. Data are means $\pm 1 \mathrm{SE}, n=3,3$, and 6 for cage, open cage, and no cages, respectively. Means sharing a common letter do not differ significantly at $P<0.05$ (Tukey HSD test).

in Experiment 3, see Tables $2 \mathrm{C}$ and $3 \mathrm{C}$ for these other variables) on numbers of recruits on caged reefs only, revealed that the bass residing in cages had no effect on recruitment of either species (Lythrypnus: $F_{1,10}=$ 0.04, $P=0.8$; Coryphopterus: $F_{1,10}=0.04, P=0.8$; adjusted least squares mean numbers of recruits $[ \pm$ pooled SE] on reefs with no resident bass $[n=9]$ vs. reefs with resident bass $[n=6]: 27.4 \pm 2.3$ vs. 26.6 \pm 2.8 and $1.9 \pm 0.4$ vs. $2.0 \pm 0.5$ for Lythrypnus and Coryphopterus, respectively). Other than the small kelp bass that resided on the six caged reefs, there were no other predators that took up residence on any of the reefs (i.e., all other predators were transient visitors).

Cage artifacts did not appear to affect the abundance of known or potential predators of the gobies (number of fish within $1 \mathrm{~m}$ of each reef [mean $\pm 1 \mathrm{SE}$ ], for the basses: $1.2 \pm 0.5,1.7 \pm 0.5$, and $1.6 \pm 0.3$ for reefs with no cage $[n=6]$, open cages $[n=15]$, and complete cages $[n=15]$, respectively; for the wrasses: 1.8 $\pm 0.7,1.0 \pm 0.2$, and $1.1 \pm 0.3$ for the three treatments in the same order). A two-way ANOVA, which included the factors predation treatment and row, indicated that these means did not differ significantly $\left(F_{2,31}\right.$ 
$=0.4, P=0.68$ for the basses and $F_{2,32}=1.7, P=$ 0.20 for the wrasses).

\section{DisCUSSION}

A variety of processes affected recruitment of the two fishes I studied. I first discuss each process independently, relating the results of this study to previously published work, which has generally explored these processes independently. I then evaluate the relative importance of the processes I explored and discuss some of the issues involved in determining the relative importance of multiple causal processes, using examples from this study.

\section{Spatially variable recruitment}

Variable supply of larvae to benthic populations has been emphasized as a primary cause of variation in the density of these populations (e.g., Doherty and Williams 1988, Underwood and Fairweather 1989, Sale 1990). Spatially variable recruitment patterns, such as the location effects I found, are often thought to be caused by variations in larval supply. However, without directly measuring larval abundance, the extent to which such variable recruitment reflects variation in larval supply cannot be known. The effects of reef location (row and position effects) that I found could have been caused by spatially variable larval supply, settlement preferences, or factors causing variable persistence after settlement. Shulman (1985a) found that recruitment of Caribbean reef fishes also increased with distance from a large reef and attributed this to variable persistence after settlement. Regardless of their actual cause or causes, the location effects I found measure the magnitude of natural spatial variation in input of recruits found in my system. Hence, at the scale over which the location effects were detected, the importance of variable input of recruits in this system can be assessed by comparing the contribution of location effects to spatial patterns of recruitment among reefs with the contributions of intra-, interspecific, and predatory effects to patterns in recruit density. If the location effects were actually caused by variable supply of larvae, then these comparisons will give a good indication of the relative importance of larval supply in this system. Alternatively, if the location effects were generated by settlement or postsettlement processes, then these comparisons will overestimate the importance of spatial variation in larval supply. (See Discussion: The relative importance of factors affecting recruitment for these comparisons).

\section{Effects of conspecifics}

Conspecifics have been found to affect the recruitment of a number of reef fishes; the effects have been both negative (Sale 1976, Forrester 1995) and positive (Sweatman 1983, 1985, Jones 1987b, Booth 1992). The species having positive effects ("recruitment facilitation") were all tropical damselfishes: Chromis caerulea
(Sweatman 1985), Dascyllus albisella (Booth 1992), Dascyllus aruanus (Sweatman 1983, 1985, Jones 1987b), and Dascyllus reticulatus (Sweatman 1983, 1985). This study shows that the phenomenon of recruitment facilitation is not confined to tropical damselfishes, since it is clearly evident in one temperate goby (Lythrypnus dalli) and may be present in another (Coryphopterus nicholsii). The mechanism(s) by which resident Lythrypnus facilitate recruitment of conspecifics is (are) not known (see Sweatman 1983 for a thorough discussion of potential causes of recruitment facilitation), but it appears that damselfish larvae preferentially settle at sites with high densities of conspecifics (Sweatman 1985, 1988, Booth 1992). The species that have been shown to exhibit recruitment facilitation (excluding the equivocal Coryphopterus nicholsii) share a number of characteristics that may predispose them to this behavior and enable predictions to be made about which other species are likely to facilitate recruitment. These five species are all small, relatively sedentary planktivores. Their small size may render them especially susceptible to predators, so migration to better sites after settlement may be particularly risky; hence, selecting a good recruitment site at the outset may be very important. Also, living in high density local populations (as would be created by recruitment facilitation) may be less costly for planktivores than for benthic feeding fishes, since planktonic food is renewed rapidly compared to many benthic resources.

Facilitation of recruitment by reef residents has consequences both for populations and the individuals living within them. From a population perspective, variation in density among local populations will be exaggerated by this positively density-dependent process. Dense populations will become even more dense relative to populations that had initially low densities. A documented consequence of this population level effect is reduced growth of individuals in the high density populations: Dascyllus albisella (Booth 1995), D. aruanus (Forrester 1990), and Lythrypnus dalli (Steele 1995) all suffer reduced growth at high densities. All of the studies that have documented the aforementioned consequences of recruitment facilitation were done on small isolated reefs (Sweatman 1983, 1985, Jones $1987 b$, Forrester 1990, Booth 1992, 1995, Steele 1995, this study), where rates of successful migration among local populations are low. It is not clear, however, if the consequences of recruitment facilitation will be as severe on large continuous reefs, where a considerable proportion of the total populations of these species live (D. aruanus: G. E. Forrester, personal communication; D. albisella and L. dalli: M. A. Steele, personal observation), and where movement among patches of suitable habitat may be less risky.

\section{Interspecific competition}

This study joins a growing list of studies that have failed to detect strong effects of interspecific compe- 
tition on population abundances of reef fishes (e.g., Doherty 1982, 1983, Jones 1987a, 1988, Roberts 1987). However, in contrast, several other studies have detected significant competitive effects, both on recruitment (Shulman et al. 1983, Sweatman 1985, Jones $1987 b$ ) and on the density or distribution of older reef fishes (e.g., Hixon 1980, Larson 1980, Robertson and Gaines 1986, Schmitt and Holbrook 1990). Given the mixed evidence, the only thing that seems certain is that the influence of interspecific competition on population abundance of reef fishes will vary among species and systems.

\section{Predation}

Predators can affect the abundance of their prey via a complex variety of direct and indirect effects (e.g., Wootton 1992, 1993), and sorting out the relative importance of each type of effect can prove challenging. Predators affected the recruitment of Lythrypnus in two ways: directly, and indirectly via effects mediated through recruitment facilitation. Since predators reduced the density of older resident Lythrypnus, recruitment declined because there were fewer residents present to facilitate it (an interaction chain, sensu Wootton 1993). Hence, the total observed effect of predators on recruitment of Lythrypnus is the sum of their direct and indirect effects.

I evaluated the relative importance of the direct and indirect components of the effect of predators on Lythrypnus both graphically and statistically. I first describe the graphical approach. In Fig. 5, the difference between the elevation of the two lines represents the magnitude of the direct effect of predators. The indirect effect of predators is caused by them reducing the average density of residents from $\mathrm{RES}_{\mathrm{np}}$ to $\mathrm{RES}_{\mathrm{p}}$. The reduction in recruitment associated with this loss of residents is the difference between the points $R_{\mathrm{nf}}$ and $R_{\mathrm{p}}$. This graphical approach indicates that the direct effect of predators was much more important $(\approx$ seven times larger) than the indirect effect.

Alternatively, the adjusted LS means from two different ANCOVA models can be used to calculate the magnitude (the intensity) of the direct effect of predators (from one model), and the total effect of predators (from the other model), and then the magnitude of the indirect effect can be determined by subtracting the direct effect from total effect. Using the adjusted LS means for the two predation treatments (predators present and predators absent) calculated from the model presented in Table $2 \mathrm{C}$, the intensity of the direct effect of predators is $48.9 \%$. This ANCOVA model can be used to calculate the direct effect of predators because the indirect effect mediated via recruitment facilitation has been removed by adjusting the means for the slope of the line representing the relationship between recruitment and resident Lythrypnus density. The LS means from a model that excludes resident "Lythrypnus density" can be used to calculate the total effect of predators because the means are no longer adjusted for the slope of the recruitment facilitation relationship. The intensity of total predator effect thus calculated is $53.8 \%$. Hence, the indirect effect of predators was to reduce recruitment by only $4.9 \%$ (indirect effect $=$ total effect - direct effect $=53.8 \%-48.9 \%$ ) .

The two approaches for estimating the relative magnitudes of the direct and indirect effects of predators lead to the same conclusion: the direct effect of predators on recruitment of Lythrypnus was much stronger than the indirect effect mediated through recruitment facilitation. While, for Lythrypnus, the indirect effect of predators on recruitment was small relative to the direct effect, for species that facilitate recruitment more strongly (e.g., the damselfishes Sweatman [1985] studied), this indirect pathway may prove to be an important source of predator effects on recruitment.

Even though only a few studies have clearly demonstrated that predators reduce recruitment of reef fishes (for review see Hixon 1991), it is not surprising that recruitment of Lythrypnus was directly reduced by predators, since predation has been shown to affect the abundance of a great variety of taxa in many diverse habitats (for review see Sih et al. 1985). It is striking, however, that predators did not consistently reduce recruitment of Coryphopterus. Why the two gobies were not affected similarly by the predator manipulation is unclear; potential causes of this species-specific difference fall into two groups: genuine biological differences or differential susceptibility to some type of cage artifact. A number of lab and field studies have demonstrated that these two fishes differ in their susceptibility to predators: in microhabitats similar or identical to those provided on the experimental reefs, Lythrypnus is always more susceptible to predation than is Coryphopterus (M. A. Steele, unpublished data). This species-specific difference in susceptibility to predation likely results from Lythrypnus being brightly colored, more active, and smaller than the cryptic Coryphopterus. However, the difference between the two species in their risk of predation is probably not as great as this study suggests. I have found evidence indicating that the partial cages I used somehow disproportionately reduce the ability of predators to consume Coryphopterus relative to Lythrypnus (Steele 1996). Given this potential cage effect on the ability of predators to eat Coryphopterus and evidence from other experiments showing predator effects on Coryphopterus (Steele 1996; M. A. Steele, unpublished data), it is probably not reasonable to conclude from this study that recruitment of Coryphopterus is unaffected by predation.

Compared to many systems (e.g., tropical reefs), the system I worked with is fairly simple: at Santa Catalina Island, one predator, the kelp bass, is probably responsible for the vast majority of mortality inflicted upon the two gobies in all of the microhabitats that they use. Even in this relatively simple, one predator 
TABLE 4. Contributions of factors affecting recruitment.

\begin{tabular}{|c|c|c|c|c|}
\hline \multirow[b]{2}{*}{ Factor } & \multicolumn{2}{|c|}{ Lythrypnus } & \multicolumn{2}{|c|}{ Coryphopterus } \\
\hline & $\begin{array}{c}\text { Intensity } \\
(\%)\end{array}$ & $\begin{array}{c}\% \text { of } \\
\text { explained } \\
\text { variance }\end{array}$ & $\begin{array}{l}\text { Intensity } \\
(\%)\end{array}$ & $\begin{array}{c}\% \text { of } \\
\text { explained } \\
\text { variance } \dagger\end{array}$ \\
\hline \multicolumn{5}{|c|}{ A) Effects including predation (Experiment 3) } \\
\hline Reef Location & 29 & 15.4 & 94 & 51.0 \\
\hline Conspecifics & +18 & 11.5 & +60 & 49.0 \\
\hline Heterospecifics & -2 & 0 & +44 & 0 \\
\hline Predators§ & -49 & 73.1 & -3 & 0 \\
\hline \multicolumn{5}{|c|}{ B) Effects in the absence of predators (Experiments 1 and 2 combined) } \\
\hline Reef Location & $212 \pm 59$ & $87 \pm 9$ & $92 \pm 61$ & $33 \pm 33$ \\
\hline Conspecifics & $+36 \pm 4$ & $13 \pm 9$ & $+14 \pm 8$ & \\
\hline Heterospecifics & $+12 \pm 16$ & 0 & $+36 \pm 42$ & $17 \pm 17$ \\
\hline \multicolumn{5}{|c|}{$\begin{array}{l}\text { Notes: Intensity is the difference between means for treatments (or locations) divided by the } \\
\text { mean recruitment to predator-free reefs for each experiment. Percent of explained variance is } \\
\text { based on } \omega^{2} \text { from ANCOVA models that include only main effects. For details, see Methods: } \\
\text { Analysis of experiments. } \\
\dagger \text { In the absence of predators (Experiments } 1 \text { and } 2 \text { combined) explained variance does not } \\
\text { sum to } 100 \% \text { because none of the factors investigated explained any variance in Experi- } \\
\text { ment } 1 . \\
\ddagger \text { Effects attributed to reef location are the effects of row and position, combined when both } \\
\text { were detected. These effects have no associated sign because they represent the absolute dif- } \\
\text { ference between the best and worst reef locations. } \\
\S \text { Predator effect }=\text { direct effect (for explanation, see Discussion: Predation). }\end{array}$} \\
\hline
\end{tabular}

system, it appears that the strength of predator effects are species specific. Furthermore, I have found that the species-specific risk of predation that the two gobies face is dependent upon microhabitat (M. A. Steele, unpublished data), so it is probably unwise to extrapolate the results of this study to other microhabitats used by the gobies, such as vertical rock walls where Lythrypnus reach their highest densities. Since it seems that the effects of predators will vary among species and even among habitats, we will need to explore the determinants of predation risk to understand better the impact of predators on reef fish populations.

\section{The relative importance of factors affecting recruitment}

After decades of emphasis on single factor models to explain population attributes, ecologists now generally agree that population attributes are most often determined by multiple processes (e.g., Quinn and Dunham 1983, Welden and Slauson 1986, Hixon 1991, Jones 1991, Sale 1991). However, while the plurality of causal mechanisms is widely appreciated, few operational frameworks have been developed that allow the relative importance (sensu Welden and Slauson 1986) of various causal factors to be assessed. To assess relative importance, two main questions must be resolved: (1) what is the contribution of each process to the pattern of interest?, and (2) what conditions alter the contributions of the processes?

I used two measures to quantify the contributions of processes that affected spatial patterns of recruitment on my experimental reefs: variance components $\left(\omega^{2}\right.$ of Winer et al. 1991) and process intensity. Variance components indicate how much of the total variation is explained by each process, while intensity measures the magnitude of the effect of a process. I used both methods because, alone, neither is an entirely satisfactory measure of the contribution of a particular process. Variance components confound the magnitude of an effect with its variability among replicates (Underwood and Petraitis 1994) and intensity ignores variability among replicates. However, some of the processes I investigated interacted statistically, and when interactions among processes exist, there is no completely acceptable means of comparing quantitatively the relative importance of each process (Underwood and Petraitis 1994). Simplistically, to allow quantitative comparisons among processes, and to illustrate the shortcomings of these approaches, I have calculated $\omega^{2}$ and intensity from ANCOVA models that included only main effects and no interactions (Table 4).

Regardless of whether the effects were measured as variance components or intensities, in the experiments done in the absence of predators (Experiments 1 and 2 ), reef location affected the recruitment of both gobies more strongly than did conspecifics or competitive interactions with heterospecifics (Table 4B). This result supports the central tenet of the "recruitment limitation" hypothesis (Doherty 1981): variation in recruitment was more important than reef-based processes in determining spatial patterns of abundance in these two fishes. For Lythrypnus, this interpretation of the importance of reef location (and hence, the importance of recruitment limitation) changes drastically when predation is also considered. Based on $\omega^{2}$ and intensity, predation was the most important process affecting recruitment of Lythrypnus (Table 4A). In contrast, reef 
location maintained its position of importance and predation was unimportant for Coryphopterus (Table 4A).

Neither of these interpretations of the relative impostance of processes is entirely accurate. Predation and reef location interacted statistically, so their effects were interdependent. While the values in Table 4A suggest some significant contributions of reef location to patterns of recruitment, this is driven only by patterns on predator-free reefs. This is clearly evident if Experiment 3 is analyzed as two separate units, one done in the presence of predators, the other conducted without predators. In the absence of predation, reef location was important for both species, explaining 51 and $63 \%$ of the total variation and having intensities of 64 and $166 \%$, for Lythrypnus and Coryphopterus, respectively. In contrast, on reefs exposed to predators, reef location explained 3 and $0 \%$ of the total variation, and had intensities of 7 and 24\%, for Lythrypnus and Coryphopterus, respectively. Moreover, while reef location had statistically significant effects in the absence of predators $(P<0.002$, for both species $)$, it did not where predators were present ( $P>0.13$, for both species). So, predators eliminated spatial variation in recruitment caused by reef location (Fig. 9). To do this, predators must have consumed recruits in a density-dependent manner, with their greatest effects occurring in areas with the highest densities of recruits.

While this study was not designed to test for densitydependent predation, other studies that I have conducted on these fishes (Steele 1995) support the hypothesis that predators induce density-dependent mortality in these two reef fishes. This possibility is intriguing, and it requires that some of the thinking regarding recruitment limitation be reconsidered. Generally, it has been thought that, so long as input into local populations is low enough that resources do not become limiting, then, in the absence of large variations in mortality (Warner and Hughes 1988), variation in supply of recruits will determine any variation in density among local populations (Doherty 1983, Victor 1986, Mapstone and Fowler 1988, Warner and Hughes 1988, Doherty and Fowler 1994). However, any strong density-dependent mortality will destroy the relationship between input and subsequent numbers within populations. Predators can induce density-dependent mortality without resources for their prey ever becoming limiting, for example, by having Type III functional responses (Holling 1959), or by having aggregative responses to prey density (Murdoch and Oaten 1975). Hence, recruitment limitation may not occur even when resources are not limiting.

Qualitatively, it seems fair to conclude that predation was vastly more important than reef location because it eliminated spatial patterns in recruitment that otherwise would have existed (see Fig. 9). So, for the two gobies I studied, a postsettlement process (predation) was much more important in setting spatial patterns in reef fish density than was larval supply, or whatever process, or set of processes, was responsible for causing reef location effects. The other postsettlement processes that I explored differed in their importance: neither inter- nor intraspecific competition played much of a role in setting spatial patterns in abundance. And, while positive effects of conspecifics (recruitment facilitation) clearly altered patterns of recruitment in Lythrypnus, and possibly affected Coryphopterus recruitment, these effects were slight relative to the effects of predators. Of course, these conclusions must be confined to the spatial and temporal scales of this study. On a cautionary note, in this study, within 3.5 wk of settlement, postdispersal processes had eliminated much of the natural variation in recruitment: this indicates that using recruitment surveys, which are often done months after settlement (e.g., Doherty and Fowler 1994), to infer patterns of settlement can be very misleading.

By knowing that, in addition to generally reducing densities of recruits, predators can reduce spatial variation in recruitment, predictions can be made regarding the potential importance of processes that affect populations of the two gobies at other times and places, at least at similar temporal and spatial scales. For example, at those times or places where predators are rare, the processes that generate spatial variation in input to local populations should play a large role in setting spatial patterns of recruitment. In contrast, in situations where predator densities are high, these same processes would be expected to have very little effect on spatial patterns of recruitment because predators would dampen spatial variation created by variable input.

\section{Conclusions}

The current understanding of the relative importance of processes that cause input to vary among open local populations vs. processes that later act to alter patterns of input is not profound. This study demonstrates that postdispersal processes, especially predation, can greatly modify patterns of input among local populations. By concurrently manipulating some of the factors that are thought to subsequently modify patterns of input, I was able to compare the effects of these processes within a common framework. Further, I was able to relate the effects of the investigated processes to naturally occurring spatial variation in input. This approach, factorial manipulation of causal processes, is perhaps the strongest means of empirically evaluating the relative importance of multiple causal processes, and it is the best way to detect interactions among processes. Had I not experimentally eliminated predators from some reefs, based on data from only reefs exposed to predators, I would have concluded that spatial variation in input to the populations of gobies was slight: the important role of predation as a modifier of the influences of reef location on input could not have been realized. However, one cost of using factorial ex- 
periments is that a great number of experimental units are required, and to achieve this, usually, the manipulations can only be made at small spatial scales. Such limitations of the experimental approach necessitate the use of correlative approaches (i.e., surveys) at larger spatial and temporal scales. By comparing the results of the two types of studies, we can ascertain whether mechanisms that influence populations at the small scales of experiments have similar consequences at larger scales.

Whether an experimental or a correlative approach is used, some means of evaluating the relative importance of multiple causal processes is needed. Yet, commonly used quantitative indices of relative importance $\left(r^{2}, \omega^{2}\right.$, intensity, or "effect size") leave much to be desired when processes interact, as they did in this study. In such cases, it will be essential to understand the functional relationships among the causal processes, so that these relationships can then be incorporated into mechanistic models that allow prediction of the relative importance of the various processes under a wide range of conditions (e.g., during periods of low vs. high input to local populations, or during periods of low vs. high predator abundance).

\section{ACKNOWLEDGMENTS}

I thank S. Anderson, B. Fredericks, M. Hearne, S. Lonhart, and D. Sabbath for seemingly endless hours of underwater assistance. S. Anderson, A. Brooks, M. Carr, J. Caselle, J. Estes, P. Fairweather, G. Forrester, S. Holbrook, R. Schmitt, M. Shulman, C. Tyler, and R. Warner provided helpful comments on versions of this manuscript. T. Anderson, K. Behrents (Hartney), M. Carr, T. Collier, G. Forrester, K. Lafferty, C. Osenberg, P. Raimondi, and C. St. Mary offered additional useful suggestions and ideas. D. Bocskai helped me in many ways. This work formed part of my Ph.D. dissertation, and my advisor, S. Holbrook, gave me intellectual, logistical, and financial assistance throughout its duration. The staff at the Wrigley Marine Science Center provided logistic support for this research. Grants from NSF (OCE 91-82941 to R. J. Schmitt and S. J. Holbrook), Sigma Xi, and the Lerner-Gray Fund for Marine Research (American Museum of Natural History) provided funds for this research. Regents and Continuing Graduate Student Fellowships from the University of California, and scholarships from the International Women's Fishing Association provided further support for the author. This is Contribution Number 190 from the Wrigley Marine Science Center at Catalina.

\section{Literature Cited}

Behrents, K. C. 1983. The comparative ecology and interactions between two sympatric gobies (Lythrypnus dalli and Lythrypnus zebra). Dissertation. University of Southern California, Los Angeles, California, USA.

1987. The influence of shelter availability on recruitment and early juvenile survivorship of Lythrypnus dalli Gilbert (Pisces: Gobiidae). Journal of Experimental Marine Biology and Ecology 107:45-59.

Booth, D. J. 1992. Larval settlement patterns and preferences by domino damselfish Dascyllus albisella Gill. Journal of Experimental Marine Biology and Ecology 155:85-104. 1995. Juvenile groups in a coral-reef damselfish: density-dependent effects on individual fitness and population demography. Ecology 76:91-106.

Carr, M. H., and M. A. Hixon. 1995. Predation effects on early post-settlement survivorship of coral-reef fishes. Marine Ecology Progress Series 124:31-42.

Caswell, H. 1978. Predator-mediated coexistence: a nonequilibrium model. American Naturalist 112:127-154.

Connell, J. H. 1985. The consequences of variation in initial settlement vs. post-settlement mortality in rocky intertidal communities. Journal of Experimental Marine Biology and Ecology 93:11-45.

Doherty, P. J. 1981. Coral reef fishes: recruitment-limited assemblages? Proceedings of the 4th International Coral Reef Symposium 2:465-470.

- 1982. Some effects of density on the juveniles of two species of tropical, territorial damselfishes. Journal of Experimental Marine Biology and Ecology 65:249-261. 1983. Tropical territorial damselfishes: is density limited by aggression or recruitment? Ecology 64:176-190. . 1991. Spatial and temporal patterns in recruitment. Pages 261-293 in P. F. Sale, editor. The ecology of fish on coral reefs. Academic Press, San Diego, California, USA. Doherty, P. J., and T. Fowler. 1994. An empirical test of recruitment limitation in a coral reef fish. Science 263:935939.

Doherty, P. J., and P. F. Sale. 1985. Predation on juvenile coral reef fishes: an exclusion experiment. Coral Reefs 4 : 225-234.

Doherty, P. J., and D. McB. Williams. 1988. The replenishment of coral reef fish populations. Oceanography and Marine Biology Annual Reviews 26:487-551.

Forrester, G. E. 1990. Factors influencing the juvenile demography of a coral reef fish. Ecology 71:1666-1681.

- 1995. Strong density-dependent survival and recruitment regulate the abundance of a coral reef fish. Oecologia 103:275-282.

Hixon, M. A. 1980. Competitive interactions between California reef fishes of the genus Embiotoca. Ecology 61: 918-931.

. 1991. Predation as a process structuring coral reef fish communities. Pages 475-508 in P. F. Sale, editor. The ecology of fish on coral reefs. Academic Press, San Diego, California, USA.

Hixon, M. A., and J. P. Beets. 1993. Predation, prey refuges, and the structure of coral-reef fish assemblages. Ecological Monographs 63:77-101.

Holling, C. S. 1959. The components of predation as revealed by a study of small-mammal predation of the European pine sawfly. Canadian Entomologist 91:293-320.

Jones, G. P. 1987a. Competitive interactions among adults and juveniles in a coral reef fish. Ecology 68:1534-1547.

. $1987 b$. Some interactions between residents and recruits in two coral reef fishes. Journal of Experimental Marine Biology and Ecology 114:169-182.

1988. Experimental evaluation of the influence of habitat structure and competitive interactions on the juveniles of two coral reef fishes. Journal of Experimental Marine Biology and Ecology 123:115-126.

1990. The importance of recruitment to the dynamics of a coral reef fish population. Ecology 71:1691-1698.

1991. Postrecruitment processes in the ecology of coral reef fish populations: a multifactorial perspective. Pages 294-330 in P. F. Sale, editor. The ecology of fish on coral reefs. Academic Press, San Diego, California, USA.

Larson, R. J. 1980. Competition, habitat selection, and the bathymetric segregation of two rockfish (Sebastes) species. Ecological Monographs 50:221-239.

Mapstone, B. D., and A. J. Fowler. 1988. Recruitment and the structure of assemblages of fish on coral reefs. Trends in Ecology and Evolution 3:72-77.

Miller, D. J., and R. N. Lea. 1976. Guide to the coastal marine fishes of California. California Department of Fish and Game, Fish Bulletin 157:1-249. 
Murdoch, W. W., and A. Oaten. 1975. Predation and population stability. Advances in Ecological Research 9:1-132.

Quinn, J. F., and A. E. Dunham. 1983. On hypothesis testing in ecology and evolution. American Naturalist 122:602617.

Roberts, C. M. 1987. Experimental analysis of resource sharing between herbivorous damselfish and blennies on the Great Barrier Reef. Journal of Experimental Marine Biology and Ecology 111:61-75.

Robertson, D. R., and S. D. Gaines. 1986. Interference competition structures habitat use in a local assemblage of coral reef surgeonfishes. Ecology 67:1372-1383.

Sale, P. F. 1976. The effect of territorial adult pomacentrid fishes on the recruitment and survival of juveniles on patches of coral rubble. Journal of Experimental Marine Biology and Ecology 24:297-306.

1990. Recruitment of marine species: is the bandwagon rolling in the right direction? Trends in Ecology and Evolution 5:25-27.

1991. Reef fish communities: open nonequilibrial systems. Pages 564-598 in P. F. Sale, editor. The ecology of fish on coral reefs. Academic Press, San Diego, California, USA

Schmitt, R. J., and S. J. Holbrook. 1990. Population responses of surfperch released from competition. Ecology 71:1653-1665.

Shulman, M. J. 1985a. Recruitment of coral reef fishes: effects of distribution of predators and shelter. Ecology 66: $1056-1066$.

. 1985b. Variability in recruitment of coral reef fishes. Journal of Experimental Marine Biology and Ecology 89: 205-219.

Shulman, M. J., J. C. Ogden, J. P. Ebersole, W. N. McFarland, S. L. Miller, and N. G. Wolf. 1983. Priority effects in the recruitment of juvenile coral reef fishes. Ecology 64:15081513

Sih, A., P. Crowley, M. McPeek, J. Petranka, and K. Strohmeier. 1985. Predation, competition, and prey communities: a review of field experiments. Annual Review of Ecology and Systematics 16:269-311.

Steele, M. A. 1995. Effects of predators and competitors on populations of two temperate reef fishes. Dissertation. University of California, Santa Barbara, California, USA.

- 1996. Effects of predators on reef fishes: separating cage artifacts from effects of predation. Journal of Experimental Marine Biology and Ecology 198:249-267.

Sweatman, H. P. A. 1983. Influence of conspecifics on choice of settlement sites by larvae of two pomacentrid reef fishes (Dascyllus aruanus and D. reticulatus) on coral reefs. Marine Biology 75:225-229.

. 1985. The influence of adults of some coral reef fishes on larval recruitment. Ecological Monographs 55: 469-485.

1988. Field evidence that settling coral reef fish larvae detect resident fishes using dissolved chemical cues. Journal of Experimental Marine Biology and Ecology 124: 163-174.

Underwood, A. J., and P. G. Fairweather. 1989. Supply-side ecology and benthic marine assemblages. Trends in Ecology and Evolution 4:16-19.

Underwood, A. J., and P. S. Petraitis. 1994. Structure of intertidal assemblages in different locations: how can local processes be compared? Pages 39-51 in R. E. Ricklefs and D. Schluter, editors. Species diversity in ecological communities. University of Chicago Press, Chicago, Illinois, USA.

Victor, B. C. 1983. Recruitment and population dynamics of a coral reef fish. Science 219:419-420.

. 1986. Larval settlement and juvenile mortality in a recruitment-limited coral reef fish population. Ecological Monographs 56:145-160.

Warner, R. R., and T. P. Hughes. 1988. The population dynamics of reef fishes. Proceedings of the Sixth International Coral Reef Symposium, Townsville, Australia 1:149-155.

Welden, C. W., and W. L. Slauson. 1986. The intensity of competition versus its importance: an overlooked distinction and some implication. Quarterly Review of Biology 61:23-44.

Wiley, J. W. 1973. Life history of the western North American goby, Coryphopterus nicholsii (Bean). Transactions of the San Diego Society of Natural History 17:187-208.

. 1976. Life histories and systematics of the western North American gobies Lythrypnus dalli (Gilbert) and Lythrypnus zebra (Gilbert). Transactions of the San Diego Society of Natural History 18:169-183.

Winer, B. J., D. R. Brown, and K. M. Michels. 1991. Statistical principles in experimental design. Third edition. McGraw-Hill, New York, New York, USA.

Wootton, J. T. 1992. Indirect effects, prey susceptibility, and habitat selection: impacts of birds on limpets and algae. Ecology 73:981-991.

. 1993. Indirect effects and habitat use in an intertidal community: interaction chains and interaction modifications. American Naturalist 141:71-89. 